\title{
AISLAMIENTO Y GENOTIPIFICACIÓN DEL VIRUS DEL SÍNDROME RESPIRATORIO Y REPRODUCTIVO PORCINO (VPRRS) EN GRANJAS SEROPOSITIVAS DE LAS PROVINCIAS DE LIMAY YREQUIPA, PERÚ
}

\author{
Isolation and Genotyping of Porcine Respiratory and Reproductive \\ Syndrome Virus on Pig Farms in Lima and Arequipa, Peru
}

Mercy Ramírez V. ${ }^{1,2}$, Hermelinda Rivera G. ${ }^{1}$, Alberto Manchego S. ${ }^{1}$, Juan More B. ${ }^{1}$, Kim Lam Chiok C. ${ }^{1}$

\section{Resumen}

\begin{abstract}
El objetivo del presente estudio fue aislar e identificar el genotipo de las cepas del virus del Síndrome Respiratorio y Reproductivo Porcino (VPRRS) de granjas porcinas de las provincias de Lima y Arequipa. Se identificaron granjas porcinas seropositivas al VPRRS mediante la prueba de ELISA. Se colectaron muestras de suero de porcinos en etapa de recría, engorde y acabado de tres granjas de Lima $(A=44, B=20, C=16)$ y dos de Arequipa ( $D=32, E=92)$ en 2010. Las 204 muestras fueron procesadas en 51 mezclas de 4 muestras cada una, respetando el lugar de procedencia, para el aislamiento viral en el clon 3D4/31 de la línea celular de macrófago alveolar porcino (PAM). La identificación del genoma viral se realizó mediante la técnica de Transcripción Reversa Reacción en Cadena de la Polimerasa tipo anidada (RT-nPCR). El ADN complementario (ADNc) de cepas vacunales del VPRRS del genotipo 1 y 2 fueron utilizados como controles positivos y $\mathrm{ADNc}$ de los virus de la arteritis viral equina y peste porcina clásica y de las células PAM como controles negativos en la técnica de RT-nPCR. Se realizaron tres pasajes ciegos en la línea celular PAM con las 51 mezclas de suero antes de ser procesadas para la búsqueda de antígeno del VPRRS mediante la técnica de inmunofluorescencia directa (IF). El $19.6 \%$ (10/51) de las muestras de suero resultaron positivas al aislamiento viral por IF. El $70 \%$ (7/10) de las cepas aisladas no presentaron efecto citopático. De los 10 aislados positivos, 8 fueron confirmados como VPRRS por la técnica de RT-nPCR y 1 de las 41 mezclas negativas por IFD fue positiva al VPRRS por RT-nPCR. El 17.6\% (9/51) de las muestras resultaron positivos al VPRRS utilizando los cebadores que reconocen a la secuencia génica común al genotipo 1 y 2 del VPRRS. Todas las cepas del VPRRS confirmadas por la técnica de RT-nPCR pertenecieron al genotipo 1 . No hubo amplificación del ARN de los controles negativos. Esta es la primera evidencia del genotipo 1 del VPRRS en granjas porcinas en el Perú.
\end{abstract}

Palabras clave: porcino, virus del Síndrome Respiratorio y Reproductivo Porcino, PRRS, virus ARN, genotipo, RT-nPCR, células de macrófagos alveolares de porcino

\footnotetext{
${ }^{1}$ Laboratorio de Microbiología y Parasitología Veterinaria, Facultad de Medicina Veterinaria, Universidad Nacional Mayor de San Marcos, Lima

${ }^{2}$ E-mail: gisvet@yahoo.es
} 
The aim of this study was to isolate and genotyping the Porcine Respiratory and Reproductive Syndrome Virus (PRRSV) strain in pig farms in Lima and Arequipa, Peru. Seropositive pig farms to PRRSV were identified by ELISA test. Blood samples were collected from weaned pigs from positive pig farms in Lima $(A=44, B=20 ; C=16)$ and Arequipa $(D=32, E=92)$. The serum samples $(n=204)$ were processed in 51 pools of 4 samples each for virus isolation using Porcine Alveolar Macrophage (PAM) cell line. The genome of the virus isolated was identified by Reverse Transcription-nested Polimerase Chain Reaction (RT-nPCR). The complementary DNA (cDNA) of genotype 1 and 2 of PRRSV vaccine strains were used as positive controls and cDNA of equine viral arteritis virus, classical swine fever virus and PAM cells as negative controls in the RT-nPCR. Three blind passages in PAM cell line with each of the 51 pool were done before searching PRRSV antigen by Immunofluorescence test. The 19.6\% (10/51) of samples were positive to viral antigen by IF. The 70\% (7/10) of the isolated strains had no cytopathic effect. Eight out of ten positive samples were confirmed as PRRSV using RT-nPCR test and 1 of the 41 negative samples was positive to PRRSV by RT-nPCR. The 17.6\% (9/51) of isolated were positives to PRRSV using primers that recognize the common genomic sequence to genotype 1 and 2 of PRRSV. All the PRRSV strains confirmed by RT-nPCR test belonged to genotype 1. This is the first evidence of genotype 1-European of PRRSV in pig farms in Peru.

Key words: porcine, Porcine Reproductive and Respiratory Syndrome virus, PRRS, ARN virus, genotype, RT-nPCR, Porcine Alveolar Macrophage cell line

\section{INTRODUCCIÓN}

La enfermedad comúnmente llamada PRRS (por sus siglas en inglés «Porcine Reproductive and Respiratory Syndrome») es causada por el virus del Síndrome Respiratorio y Reproductivo Porcino (VPRRS), que emergió a fines de la década del 80 y comienzos del 90 en los EEUU y Europa (Wensvoort, 1993; Meulenberg, 2000). El virus emergente recibió varias denominaciones ante la dificultad para el aislamiento del agente causal, que se caracterizó por ocasionar partos prematuros, momificaciones fetales, nacimiento de crías muertas o débiles, alta mortalidad predestete y problemas respiratorios, especialmente en animales en crecimiento y acabado (Meulenberg, 2000; OIE, 2008). El PRRS es una de las enfermedades de mayor impacto económico para los productores de cerdo en todo el mundo, estimándose una pérdida anual de 560 millones de dólares en los EEUU (Neumann et al., 2005; Beura et al., 2010).

Actualmente, el PRRS está mundialmente distribuido y las cepas pertenecen a dos genotipos relacionados, pero antigénica y genéticamente distinguibles: el genotipo $1 \mathrm{o}$ europeo y el genotipo 2 o americano (Guarino et al., 1999; OIE, 2008; Spilman et al., 2009). Ambos genotipos tienen un alto tropismo por células de la línea monocito/macrófago, principalmente por macrófagos alveolares porcinos (PAMs) que constituyen el principal blanco para la replicación viral (Genini et al., 2008).

Se desconoce la fecha del ingreso del virus al Perú, pero a fines de la década del 90 se incrementó la frecuencia de problemas respiratorios y reproductivos en porcinos de granjas, principalmente de la zona de Lima. Actualmente, la porcicultura nacional ha mejorado notablemente por el uso de tecnología 
moderna y el mejoramiento genético de la población porcina (MINAG, 2011); sin embargo, a veces este desarrollo se ve limitado por enfermedades infecciosas como el PRRS.

En un estudio serológico realizado por Alegría et al. (1998) se detectó una prevalencia de $13.6 \%$ de VPRRS en porcinos de engorde provenientes de granjas tecnificadas de Lima. La infección estuvo presente en 6 de las 29 granjas muestreadas y en el $77 \%$ de los animales de las granjas positivas. Posteriores estudios serológicos indican que la prevalencia del VPRRS se ha incrementado (H. Rivera, comunicación personal); sin embargo, no ha habido reportes de aislamientos de cepas de VPRRS ni de los genotipos presentes en la población porcina nacional.

El objetivo del estudio fue aislar e identificar los genotipos del VPRRS que circulan en granjas porcinas de las provincias de Lima y Arequipa, como base para futuros estudios epidemiológicos y, adicionalmente, implementar la técnica de RT-PCR como una herramienta diagnóstica de alta sensibilidad y especificidad.

\section{Materiales y Métodos}

\section{Granjas Seropositivas y Muestras}

Se seleccionaron tres granjas porcinas de la provincia de Lima: A $(n=44), B(n=20)$, $\mathrm{C}(\mathrm{n}=16)$ y dos de Arequipa: $\mathrm{D}(\mathrm{n}=32)$ y $\mathrm{E}$ $(n=92)$, teniendo como criterio de selección un número mayor o igual a 600 madres en producción y al menos $30 \%$ de seroprevalencia del VPRRS en el grupo de animales de engorde de estas granjas.

Se colectaron 204 muestras de suero sanguíneo de lechones (21 a 70 días de edad) y gorrinos (71 a 140 días de edad) entre machos y hembras de las cinco granjas durante el año 2010. Con estas muestras, se hicieron 51 mezclas (pool) conformadas por 4 muestras de suero de $50 \mu 1$ cada una, obteniendo un volumen total de $200 \mu 1$ por mezcla, respetando el lugar de procedencia.

\section{Aislamiento Viral}

Se inoculó $100 \mathrm{ml}$ de cada mezcla de suero sanguíneo en una monocapa confluente de la línea celular de macrófago alveolar porcino (PAM, por su sigla en inglés), clon 3D4/31(cortesía del Dr. John Pasick, Canadá). La monocapa con los inóculos se incubaron a $37{ }^{\circ} \mathrm{C}$ por 1 hora para permitir la adsorción viral. Luego se reconstituyó con 2 $\mathrm{ml}$ de medio de cultivo celular RPMI (en inglés, Roswell Park Memorial Institute) (Sigma, USA) y $3 \%$ de suero fetal bovino, y se dejó incubando a $37{ }^{\circ} \mathrm{C}$ con una atmósfera de $5 \%$ de $\mathrm{CO}_{2}$ durante 72-96 horas. Posteriormente, se cosecharon las células infectadas, que sirvieron de inóculo en pasajes ciegos hasta por tres veces en nuevas monocapas de células PAM.

\section{Identificación del antígeno del VPRRS}

Luego de 72-96 horas de inoculación, las monocapas fueron procesadas para la identificación del antígeno viral en el aislado mediante la prueba de IF, utilizando el anticuerpo monoclonal SDOW 17 (cortesía del Dr. David Benfield, EEUU) que reconoce ambos genotipos del VPRRS (Allende et al., 2000).

Las muestras positivas fueron sometidas a dos choques térmicos $\left(-20^{\circ} \mathrm{C}\right)$ y los lisados celulares fueron centrifugados a 650 $\mathrm{g}$ por 30 minutos en una centrífuga refrigerada a $4{ }^{\circ} \mathrm{C}$. El sobrenadante fue cosechado por triplicado en viales de microcentrífuga y almacenado en volúmenes de $1 \mathrm{ml} \mathrm{a}-70{ }^{\circ} \mathrm{C}$ hasta su procesamiento para la extracción del ARN de VPRRS.

\section{Determinación del Genotipo Viral}

Se utilizó la técnica de Retrotranscriptasa Reversa-PCR tipo anidado convencional (RT-nPCR) descrita por Gilbert et al. (1997), previa optimización de la técnica uti- 
Cuadro 1. Cebadores oligonucleótidos para la amplificación y genotipificación del virus del Síndrome Respiratorio y Reproductivo Porcino por RT-nPCR

\begin{tabular}{|c|c|c|c|c|}
\hline Cebador $^{1}$ & $\begin{array}{l}\text { Tipo } \\
\text { detectado }\end{array}$ & $\begin{array}{l}\text { Secuencia } \\
\left(5^{\prime}-3^{\prime}\right)\end{array}$ & $\begin{array}{l}\text { Posición en } \\
\text { el genoma }\end{array}$ & $\begin{array}{l}\text { Tamaño del } \\
\text { producto de } \\
\text { PCR (pb) }\end{array}$ \\
\hline \multicolumn{5}{|c|}{ Externos RT-nPCR } \\
\hline $\begin{array}{l}\text { EU-F } \\
\text { ED-R }\end{array}$ & Común & $\begin{array}{l}\text { CCTCCTGTATGAACTTGC } \\
\text { AGGTCCTCGAACTTGAGCTG }\end{array}$ & $\begin{array}{l}8628-8645 \\
8863-8882\end{array}$ & 255 \\
\hline \multicolumn{5}{|c|}{ Internos RT-nPCR } \\
\hline $\begin{array}{l}\text { U1-F } \\
\text { D1-R }\end{array}$ & Eu ropeo & $\begin{array}{l}\text { GTATGAACTTGCAGGATG } \\
\text { GCCGACAATACCATGTGCTG }\end{array}$ & $\begin{array}{l}8634-8651 \\
8800-8819\end{array}$ & 186 \\
\hline $\begin{array}{l}\mathrm{U} 2-\mathrm{F} \\
\mathrm{D} 2-\mathrm{R}\end{array}$ & Americano & $\begin{array}{l}\text { GGCGCAGTGACTAAGAGA } \\
\text { GTAACTGAACACCATATGCTG }\end{array}$ & $\begin{array}{l}8713-8730 \\
8799-8819\end{array}$ & 107 \\
\hline
\end{tabular}

${ }^{1} \mathrm{~F}$ : Forward R: Reverse

lizando el ADNc de los genotipos 1 o europeo y 2 o americano del VPRRS. Asimismo, como controles negativos se usó el ARN de muestras de suero $(n=30)$ procedente de granjas negativas a VPRRS por análisis serológico realizado por más de tres años consecutivos (H. Rivera, comunicación personal) y el ARN de las células normales de PAM. Agua destilada libre de nucleasas (Ambion, The RNA Company, EEUU) fue utilizada como control de contaminación de las mezclas.

\section{Extracción de ARN}

La extracción del ARN de los aislados en cultivo celular se realizó de acuerdo a las especificaciones del kit comercial de extracción y purificación de ARN «SV Total RNA Isolation System» (Promega) y siguiendo las instrucciones del fabricante.

\section{RT-nPCR}

Para determinar el genotipo viral se siguió con el protocolo diseñado por Gilbert $e t$ al. (1997) con algunas variaciones. El RTnPCR se desarrolló en dos pasos separados, utilizando los kit comerciales de Invitrogen y Promega, siguiendo las especificaciones del fabricante.

En el primer paso se utilizó el Kit «SuperScript ${ }^{\mathrm{TM}}$ III First-Strand Synthesis SuperMix» (Invitrogen, EEUU) para la síntesis de ADN complementario (ADNc) a partir de las muestras de ARN total extraídos previamente. En el segundo paso se empleó el Kit «Go Taq ${ }^{\circledR}$ Colorless Master Mix» (Promega, USA) para la amplificación del ADN por cebadores específicos para la secuencia común a ambos genotipos y cebadores para cada uno de los genotipos del VPRRS (Cuadro 1), a partir del ADNc obtenido en el paso anterior. En ambos pasos se usó el termociclador PTC 200 (Peltier therme cycler) (MJ Research-UK). El software utilizado fue el Opticon Monitor 2, v. 2.03 (MJ Research, UK).

\section{Obtención del ADNc}

Los ARN totales extraídos fueron procesados para la obtención de una hebra de ADNc viral por acción de la enzima transcriptasa reversa del virus de la Leucemia 
Cuadro 2. Aislamiento del virus del Síndrome Respiratorio y Reproductivo Porcino (VPPRS) en línea celular de macrófago alveolar de porcino (PAM), mediante la prueba de inmunofluorescencia directa, en muestras de granjas porcinas tecnificadas y seropositivas (2010)

\begin{tabular}{lccc}
\hline \multirow{2}{*}{ Efecto citopático } & \multicolumn{3}{c}{ Muestras } \\
\cline { 2 - 4 } & $\begin{array}{c}\text { Positivas } \\
(\mathrm{n})\end{array}$ & $\begin{array}{c}\text { Negativas } \\
(\mathrm{n})\end{array}$ & $\begin{array}{c}\text { Total } \\
(\mathrm{n})\end{array}$ \\
\hline Positivo & 3 & 7 & 10 \\
Negativo & 7 & 24 & 41 \\
\hline Total & $10(19.6 \%)$ & $41(80.4 \%)$ & $51(100.0 \%)$ \\
\hline
\end{tabular}

Cuadro 3. Muestras de suero positivas y negativas al virus del Síndrome Respiratorio y Reproductivo Porcino por las técnicas de inmunofluorescencia directa y RTnPCR, provenientes de granjas porcinas tecnificadas y seropositivas (2010)

\begin{tabular}{lcccc}
\hline & & \multicolumn{2}{c}{ RT-nPCR } & Total \\
\cline { 3 - 4 } & & Positivo & Negativo & \\
\hline \multirow{2}{*}{ Inmunofluorescencia directa } & Positivo & 8 & 2 & 10 \\
& Negativo & 1 & 40 & 41 \\
\hline & Total & 9 & 42 & 51 \\
\hline
\end{tabular}

Murina Moloney (M-MLV). El ARN total se incubó junto con los oligo $(\mathrm{dT})_{20}$, hexámeros al azar, cloruro de magnesio $\left(\mathrm{MgCl}_{2}\right)$, desoxirribonucleótidos trifosfatos (dNTPs) y la transcriptasa M-MLV, según el protocolo recomendado por el fabricante. Los ADNc fueron utilizados para la reacción de PCR convencional, preferentemente, el mismo día de su síntesis.

\section{PCR Convencional}

Se preparó una mezcla de reacción para el PCR convencional utilizando los cebadores externos (EU/ED) y la Taq DNA polimerasa para la identificación del VPRRS, siguiendo las recomendaciones del fabricante en un volumen final de $20 \mu \mathrm{l} /$ muestra y tomando como referencia los parámetros establecidos por Gilbert et al. (1997).

Para la genotipificación del VPRRS se utilizaron los cebadores internos específicos U1/D1 (Europeo) y U2/D2 (Americano) en rondas separadas tomando como templado el producto obtenido en la primera amplificación. El volumen final fue de $20 \mu \mathrm{l} /$ muestra. Los productos de la PCR fueron amplificados por electroforesis en gel de agarosa al $2 \%$ teñida con bromuro de etidio y examinados sobre un transiluminador UV. 


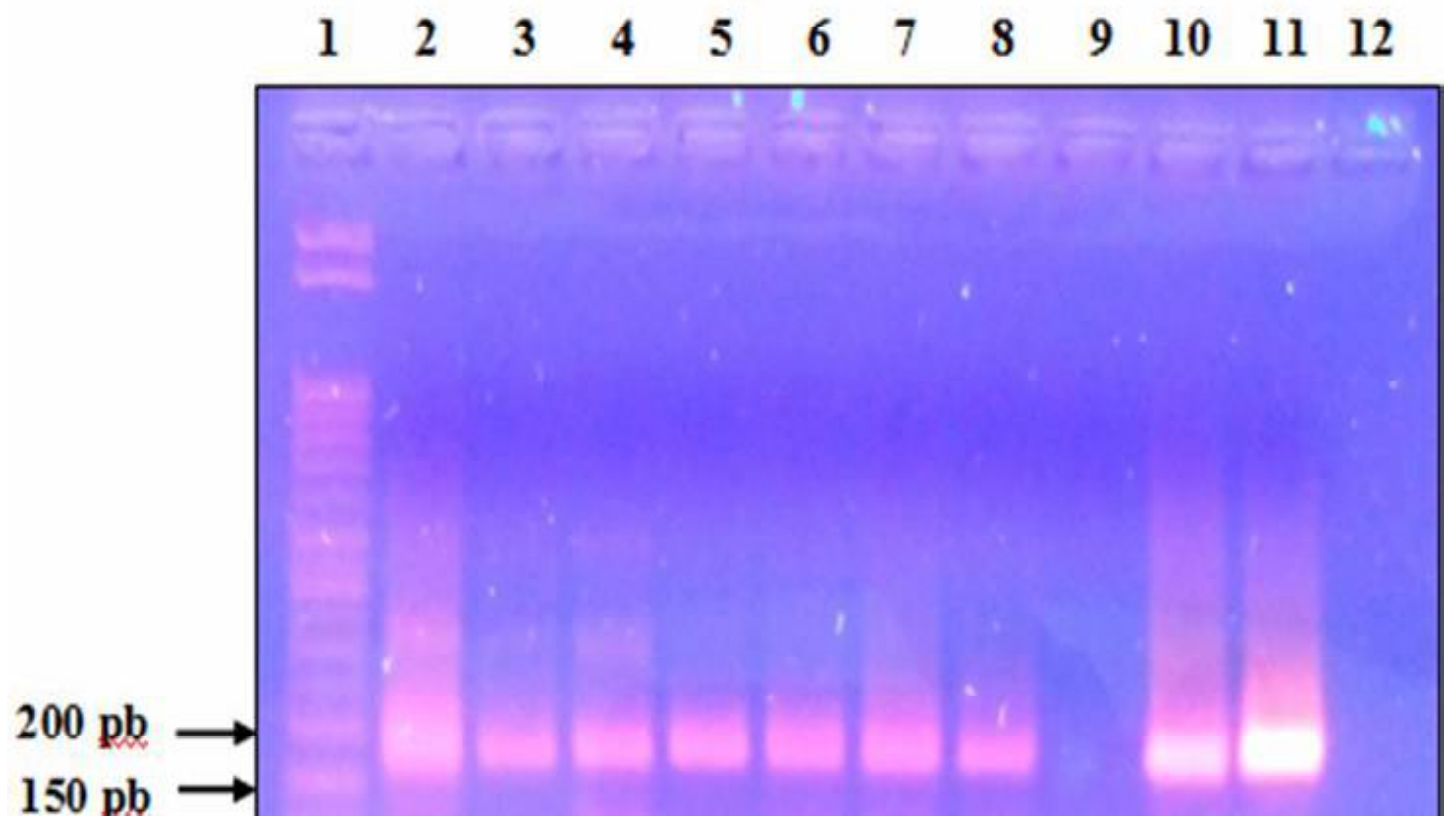

Figura 1. Bandas de amplificación de ocho aislados del VPRRS genotipo 1 (186 pb). Línea 1: marcador; líneas 2 al 8: VPRRS de campo; línea 9: control negativo (células PAM); línea agua libre de nucleasas 10: VPRRS de campo; línea 11: control positivo (VPRRS, genotipo 1); línea 12: agua libre de nucleasas

\section{Interpretación de Resultados}

La positividad de las muestras al genotipo 1 o 2 fue determinada por la presencia de bandas en el gel de agarosa según el producto esperado, teniendo como referencia el marcador de peso molecular y los controles positivos por cada genotipo.

El número de muestras positivas a antígeno viral mediante la prueba de Inmunofluorescencia directa (IF) y RT-nPCR se presentan en porcentajes.

\section{Resultados}

El 19.6\% (10/51) de las muestras de suero procesadas resultaron positivas al aislamiento viral. Asimismo, el 70\% (7/10) de las cepas aisladas no presentaron efecto citopático (NCP) (Cuadro 2).
Ocho de los 10 aislados positivos a VPRRS por IF fueron confirmados como positivos al VPRRS mediante la técnica de RT-nPCR, mientras que una de las 41 muestras negativas por IF resultó positiva mediante RT-nPCR (Cuadro 3).

Nueve de las 51 mezclas $(17.6 \%)$ resultaron positivas al VPRRS por la técnica de RT-nPCR usando los cebadores que determinan la secuencia común a ambos genotipos del VPRRS y todas pertenecieron al genotipo 1 del VPRRS. Asimismo, el 77.8 (7/9) y el $22.2 \%$ (2/9) de las muestras identificadas como genotipo 1 fueron de las granjas de Arequipa y Lima, respectivamente.

Dado que las 204 muestras de suero fueron trabajadas en mezclas (pool) de 4 sueros en uno y ante la posibilidad de que el aislado contenga más de una cepa, las 9 muestras positivas trabajadas como mezclas fue- 


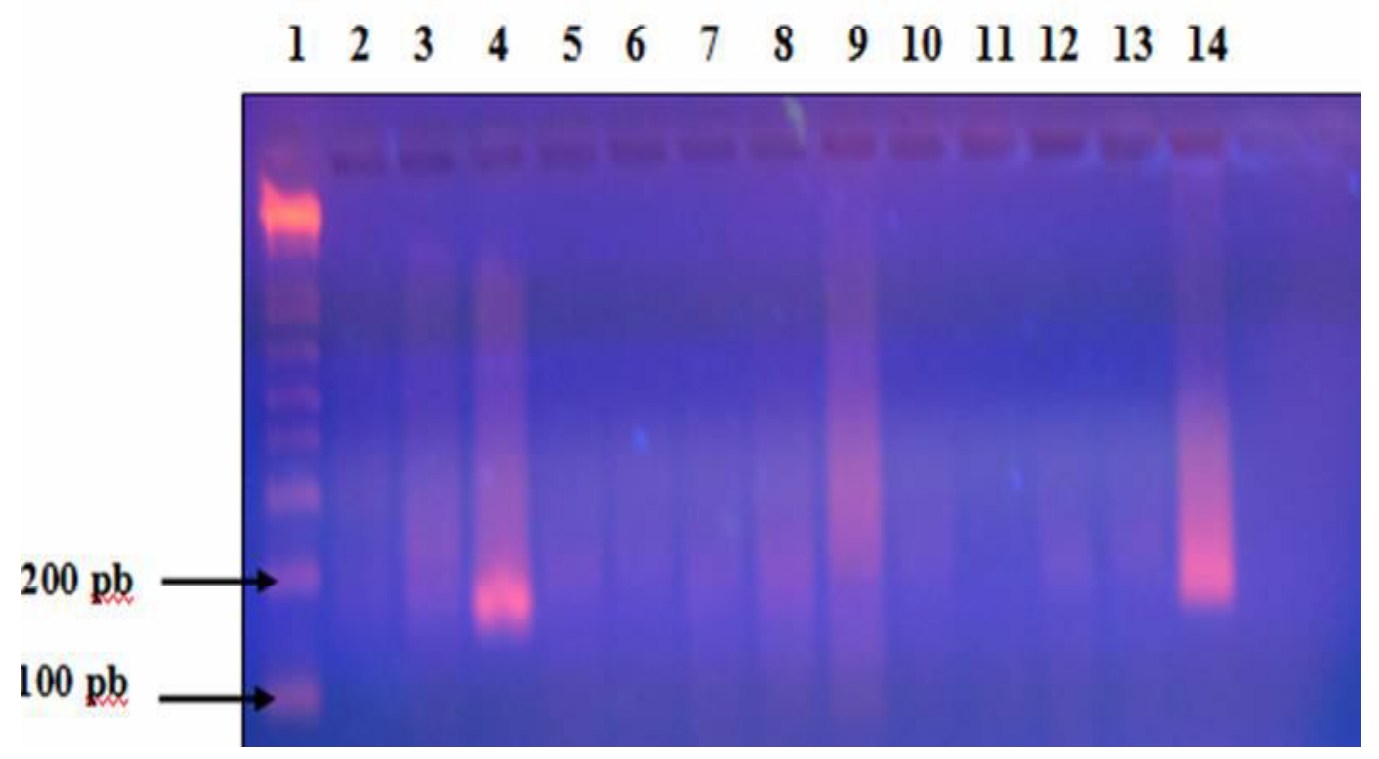

Figura 2. Banda de amplificación por RT-nPCR de las muestras negativas a aislamiento-IF. Línea 1: marcador; líneas 2 y 3: muestras de campo; línea 4: VPRRS de campo; líneas 5-10: muestras de campo; línea 11: control negativo (línea celular PAM); líneas 12 y 13: muestras de campo; línea 14: control positivo (VPRRS genotipo1- Europeo)

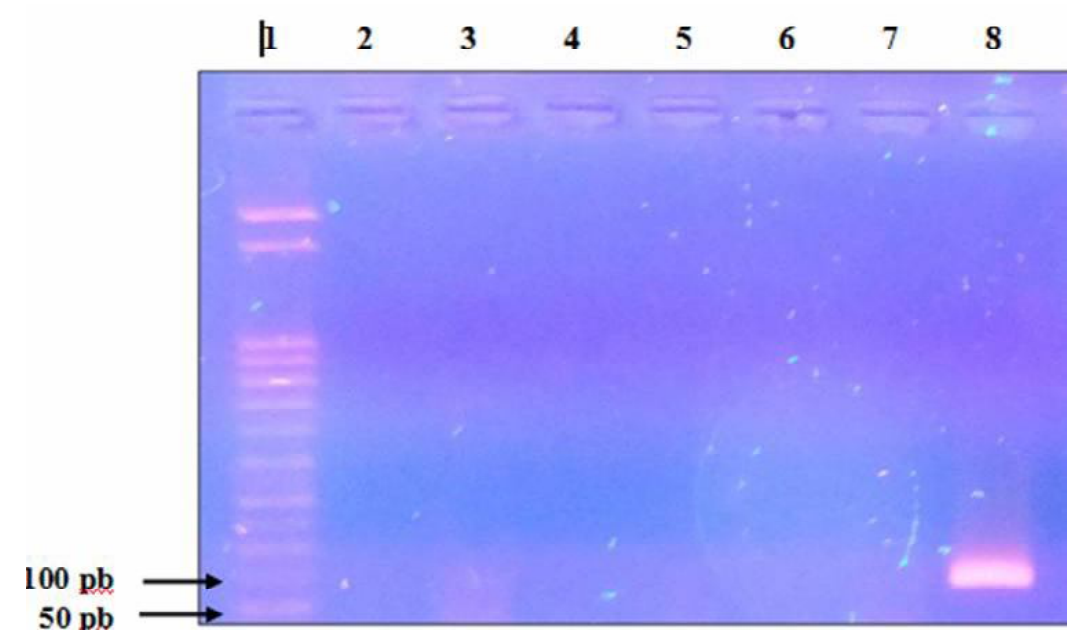

Figura 3. Banda de amplificación del control del genotipo 2 - americano del VPRRS (107 pb) determinado por RT-nPCR. Ninguna muestra resultó positiva. Línea 1: marcador; líneas 2 al 6: muestras de campo; línea 7: control negativo (línea celular PAM); línea 8: control positivo (VPRRS genotipo 2 - americano) 
ron procesadas individualmente por RT-nPCR, encontrando que solo un aislado de cada «pool» fue identificado como positivo al genotipo 1.

Las monocapas de PAM inoculadas con las muestras positivas evidenciaron efecto citopático posterior a las 48 horas de inoculadas. Asimismo, la completa destrucción de las monocapas se observó, generalmente, al cuarto día. Siete aislados no mostraron efecto citopático.

En la Fig. 1 se muestran las bandas de amplificación de ocho aislados de VPRRS genotipo 1 en gel de agarosa al 2\% teñida con bromuro de etidio. En la Fig. 2 se presentan los resultados de las muestras negativas, donde además, se observa una banda de amplificación correspondiente a la única muestra negativa por IF que resultó positiva por la técnica de RT-nPCR

\section{Discusión}

El aislamiento viral en cultivo celular es una técnica altamente específica siempre que se disponga de un sistema celular permisible al virus y de la correcta elección de la muestra. Varios autores señalan a las células PAM como el sistema celular más sensible para aislar VPRRS de muestras de suero sanguíneo, debido a que los anticuerpos presentes en el suero facilitan la replicación del virus al ingresar vía endocitosis al macrófago a través de los receptores $\mathrm{Fc}$ presentes en su membrana (Bautista et al., 1993; Yoon et al., 1997; Thacker, 2003; Rovira et al., 2007).

No se logró aislar el VPRRS en las células PAM en la mayor parte de las muestras $(82.4 \%, 42 / 51)$, pese a que el macrófago alveolar porcino es la célula más susceptible a este virus. No obstante, se sabe que esta susceptibilidad puede variar entre lotes de células (OIE, 2008). Si bien la línea empleada en el presente estudio era bastante estable, es posible que haya sido menos suscepti- ble a las cepas que circulan en las granjas porcinas del país, y que de haber empleado un cultivo primario de macrófagos alveolares de porcino, como indica Mengeling et al. (1995), se habría podido aislar más cepas virales. Además, la gran variabilidad genética y antigénica que presentan las cepas del VPRRS sugiere que el uso de un único sistema celular no sería el más adecuado para el asilamiento de cepas de campo (Reiner et al., 2009; Spilman et al., 2009).

El 70\% (7/10) de los aislados no presentaron lesión celular o efecto citopático (ECP) en las células PAM pero hubo replicación viral comprobado por la técnica de RT-nPCR. Dos de las tres muestras que produjeron ECP fueron negativas a VPRRS por RT-nPCR, indicando que las lesiones observadas en las células no correspondieron a este virus (Cuadros 2 y 3 ). En total, más del $80 \%(8 / 9)$ de los aislados no fueron citopatogénicos, indicando la posibilidad de que necesitan más de tres pasajes adicionales para manifestar ECP. Se debe considerar que los aislados provienen de muestras de suero de animales de apariencia normal, de allí que las cepas pueden ser de baja virulencia, coincidiendo con su comportamiento in vitro.

De los 10 aislados positivos a VPRRS por IF sometidos a la técnica de RT-nPCR, solo ocho fueron confirmados como VPRRS y una muestra negativa por IF resultó ser VPRRS por RT-nPCR (Cuadro 3, Figs. 1 y 2). Esto puede deberse a que la prueba de RT-nPCR es más sensible que el aislamiento viral para identificar cerdos infectados con VPRRS (Wills et al., 2003; OIE, 2008; Ruiz et al., 2009). Los dos aislados que resultaron como VPRRS por la técnica de IF y negativos a RT-nPCR fueron sin duda falsos positivos. Si bien la técnica de IF posee $99.5 \%$ de especificidad pero tiene baja sensiblidad (Collins et al., 1996), esta baja sensibilidad sumado a la falta de una cepa del VPRRS de referencia podrían haber contribuido a la detección de dos falsos positivos. 
Mediante la técnica de RT-nPCR se determinó que 9 aislados fueron VPRRS y 42 no lo fueron (Cuadro 3). Si bien es cierto que la técnica de RT-nPCR y sus variantes son extensamente utilizadas para los estudios moleculares y de diagnóstico del VPRRS por su sensibilidad y especificidad cercana al 100\% (Gilbert et al., 1997; Guarino et al., 1999; Truyen et al., 2006), también puede dar más resultados falsos negativos (Truyen et al., 2006), sobre todo cuando la PCR no está adecuadamente optimizada o cuando los cebadores no son correctamente diseñados.

Existen dos regiones altamente conservadas del genoma del VPRRS, la región ORF1b, que codifica la polimerasa viral y la región ORF7, que codifica la más abundante proteína estructural, la nucleoproteína. En el estudio se utilizaron cebadores diseñados para amplificar la región ORF1b del genoma del VPRRS con resultados satisfactorios, ya que permite la identificación viral en muestras de suero de animales vivos. Sin embargo, un estudio realizado por Truyen et al. (2006) en el que evaluaron protocolos de RT-nPCR para la identificación del VPRRS y sus genotipos, el protocolo con más ventajas utilizó cebadores diseñados para amplificar la región ORF7 del genoma de VPRRS, por lo que debe considerarse su aplicación en futuros estudios.

La ausencia de cepas del genotipo 2 de VPRRS por RT-nPCR (Fig. 3) podría deberse a la granja muestreada y al empleo de la línea celular PAM que es más sensible para las cepas del genotipo 1. La porcicultura en el país se ha desarrollado, en parte, con la importación reproductores y semen de países donde el genotipo 2 fue ampliamente difundido (Carman et al., 1995; Zimmerman et al., 1997), pudiendo haber ingresado al país en las décadas del 80 y 90 cuando el VPRRS no estaba en la lista de enfermedades a ser consideradas como barreras sanitarias. Actualmente la enfermedad es endémica a nivel global (Shi et al., 2010). Por esto, el presente estudio no descarta la presencia del genotipo 2 de VPRRS en la población porcina del país.
Más investigaciones deben realizarse con el fin de establecer el real estado del virus del genotipo 2 en mayor número de granjas con diversidad de tecnología y utilizando otras líneas celulares como MARC-145, CL2621, MA-104 que son reconocidas por su mayor susceptibilidad al aislamiento de cepas del genotipo 2 del VPRRS (Nielsen et al., 2001; OIE, 2008; Ruiz et al., 2009). Países como Chile, que maneja un estricto control sanitario, presentó brotes recientes de PRRS en sus explotaciones porcinas ocasionados por cepas del genotipo 2 con $88.9 \%$ de identidad con la cepa americana de referencia V-2332 (Ruiz et al., 2009; Rojas, 2010).

Actualmente se conoce el cuadro clínico así como la epidemiología de la enfermedad, y se dispone de vacunas para su control, pero aún falta conocer detalles de la patogénesis, biología del virus y sobre todo los aspectos inmunitarios (Mateu y Díaz, 2008). Asimismo, en el país, falta mucho por conocer sobre el agente viral y la epidemiología de esta importante enfermedad que hasta el momento está siendo identificado como parte del complejo respiratorio porcino.

\section{Conclusiones}

- Se aislaron nueve cepas del virus del Síndrome Respiratorio y Reproductivo Porcino en la línea celular de macrófagos alveolares porcinos (PAM) clon 3D4/31, confirmadas por la técnica de RT-nPCR.

- Los aislados pertenecen al genotipo 1 europeo del VPRRS.

- No se aislaron cepas del genotipo 2 americano del VPRRS.

\section{Agradecimientos}

Los autores agradecen al Dr. John Pasick, National Center for Foreign Animal Disease, (Canadá) por haber donado el clon 3D4/31 de la línea celular PAM; a la Dra. Mariluz Arainga por donar el ADNc de la 
cepa vacunal JJ882 del genotipo americano; al Dr. Bernado Prieto, Universidad de León, España, por donar el ADNc de la cepa vacunal All183 del genotipo europeo; y al Dr. Lenin Maturrano por sus valiosos comentarios sobre los resultados moleculares.

El estudio fue financiado por el Consejo Nacional de Ciencia y Tecnología con Con-

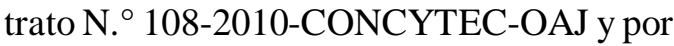
el Consejo Superior de Investigaciones (CSI) de la Universidad Nacional Mayor de San Marcos, Lima, Perú.

\section{Literatura Citada}

1. Alegría ME, Rivera H, Manchego A. 1998. Evidencia del virus del Síndrome Reproductivo y Respiratorio Porcino en porcinos de crianza tecnificada. Rev Inv Pec IVITA 9(1): 53-58.

2. Allende $R$, Laegreid WW, Kutish GF, Galeota JÁ, Wills RW, Osorio FA. 2000. Porcine Reproductive and Respiratory Syndrome Virus: Description of persistence in individual pigs upon experimental infection. J Virol 74: 1083410837.

3. Bautista EM, Sagar MG Yoon IJ, Joo HS, Collins JE. 1993. Comparison of porcine alveolar macrophages and CL 2621 for the detection of porcine reproductive and respiratory syndrome (PRRS) virus and anti-PRRS antibody. J Vet Diagn Invest 5: 163-165.

4. Beura L, Sarkar S, Kwon B, Subramaniam S, Jones C, Pattnaik A, Osorio F. 2010. Porcine Reproductive and Respiratory Syndrome Virus nonstructural protein 1â modulates host innate immune response by antagonizing IRF3 activation. J Virol 84: 1574-1584.

5. Carman S, Sanford SE, Dea S. 1995. Assessment of seropositivity to Porcine Reproductive and Respiratory Syndrome (PRRS) Virus in swine herds in Ontario, 1978 to 1982. Can Vet J 36: 776-777.
6. Collins J, Dee S, Halbur P. 1996. Laboratory diagnosis of porcine reproductive and respiratory syndrome virus infection. Swine Health Prod 4: 33-35.

7. Genini S, Peter L. Delputte T, Malinverni R, Cecere M. Stella A, Nauwynck H, Giuffra E. 2008. Genome-wide transcriptional response of primary alveolar macrophages following infection with porcine reproductive and respiratory sindrome virus. J Gen Virol 89: 2550-2564.

8. Gilbert SA, Lorochelle R, Magar R, Cho HJ, Deregt D. 1997. Typing of porcine reproductive and respiratory syndrome viruses by a multiplex PCR assay. J Clin Microbiol 35: 264-267.

9. Guarino H, Goyal SM, Murtaugh MP, Morrison RB, Kapur V. 1999. Detection of Porcine Reproductive and Respiratory Syndrome Virus by reverse transcription-polymerase chain reaction using different regions of the viral genome. J Vet Diagn Invest 11: 27-33.

10. Mateu E, Díaz I. 2008. The challenge of PRRS immunology. Vet J 177: 345351.

11. Mengeling WL, Lager KM, Vorwald AC. 1995. Diagnosis of Porcine Reproductive and Respiratory Syndrome. J Vet Diagn Invest 7: 3-16.

12. Meulenberg JM. 2000. PRRSV, the virus. Vet Res 31: 11-21.

13. [MINAG] Ministerio de Agricultura. 2011. Portal Agrario. Lima: Ministerio de Agricultura. [Internet], [6 setiembre 2011]. Disponible en: http:// www.minag.gob.pe/sector-agrario/sector-agrario.html

14. Neumann EJ, Kliebenstein JB, Johnson CD, Mabry JW, Bush EJ, Seitzinger AH, et al. 2005. Assessment of the economic impact of porcine reproductive and respiratory syndrome on swine production in the United States. J Am Vet Med Assoc 227: 385-392.

15. Nielsen HS, Oleksiewicz MB, Forsberg R, Stadejek T, Botner A, Storgaard T. 2001. Reversion of a live 
Porcine Reproductive and Respiratory Syndrome Virus vaccine investigate by parallel mutations. J Gen Virol 82: 12631272.

16. [OIE] Organización Mundial de Sanidad Animal. 2008. PRRS: the disease, its diagnosis, prevention and control. Annex 4-5 of the Report of the OIE Ad hoc Group on PRRS. Paris. 7 p.

17. Reiner $G$, Fresen $C$, Bronnert $S$, Willems H. 2009. Porcine Reproductive and Respiratory Syndrome Virus (PRRSV) infection in wild boars. Vet Microbiol 136: 250-258.

18. Rojas M. 2010. Proyecto erradicación del Síndrome Respiratorio y Reproductivo del cerdo (PRRS) en Chile. En: Memorias X Congreso Nacional de Producción Porcina. Mendoza, Argentina.

19. Rovira A, Clement T, ChristopherHennings J, Thompson B, Engle $M$, Reicks D, Muñoz-Zanzi Cl. 2007. Evaluation of the sensibility of reverse transcription polymerase chain reaction to detect Porcine Reproductive and Respiratory Syndrome Virus on individual and pooled samples from boars. $\mathbf{J}$ Vet Diagn Invest 19: 502-509.

20. Ruiz A, Neira V, Ramírez E, García A, Lecocq C, Quezada M. 2009. Estudio de la excreción y la transmisión del aislado chileno del virus del síndrome Respiratorio y Reproductivo porcino (PRRS) en animales inoculados experimentalmente y centinelas en contacto mediante RT-nPCR y ELISA. Arch Med Vet 41:221-228.

21. Shi M, Tsan-Yuk Lam T, Chung Chu H, Kin-Hei Hui R, Faaberg KS, et al. 2010. Molecular epidemiology of
PRRSV: A phylogenetic perspective. Virus Res 154: 7-17.

22. Spilman MS, Welbon C, Nelson E, Dokland T. 2009. Cryo-electron tomography of Porcine Reproductive and Respiratory Syndrome Virus: organization of the nucleocapsid. J Gen Virol 90: 527-535.

23. Thacker B. 2003. Clinical manifestations of PRRS virus. In: Zimmerman J, Yoon KJ (eds). PRRS compendium. $2^{\text {nd }}$ ed. Iowa, US A: National Pork Board. p 27-34.

24. Truyen $U$, Wilhelm S, Genzow M, Schagemann G. 2006. Porcine Reproductive and Respiratory Syndrome Virus (PRRSV): A ring test performed in Germany to assess RT-PCR detection methods. J Vet Med 53: 68-74.

25. Wensvoort G 1993. Lelystad virus and porcine epidemic abortion and respiratory syndrome. Vet Res $24: 117-$ 124.

26. Wills RW, Doster, Galeota JA, Sur JH, Osorio FA. 2003. Duration of infection and proportion of pigs persistently infected with Porcine Reproductive and Respiratory Syndrome Virus. J Clin Microbiol 41: 58-62.

27. Yoon KJ, Wu LL, Zimmerman JJ, Platt KB. 1997. Field isolates of Porcine Reproductive and Respiratory Syndrome Virus (PRRSV) vary in their susceptibility to antibody dependent enhancement (ADE) of infection. Vet Microbiol 55: 277-287.

28. Zimmerman JJ, Yoon KJ, Wills RW, Swenson SL. 1997. General overview of PRRS: A perspective from United States. Vet Microbiol 55: 187-196. 